\title{
Instituciones y gestión del desarrollo rural en Argentina
}

\author{
Mabel ManZAnal*
}

\begin{abstract}
The aim of the paper is to contextualize and analyze the rural development in Argentina, particularly the capacities of the different existing programmes on rural development to promote the sector transformation within a context of scarce resources and institutional, national, provincial and local weaknesses. In the first part our perspective on the conditions of current rural development feasibility is presented. The second part is a diagnosis on the current characteristics of rural development in a national context and its institutional situation. And finally, the third part analyses the actions of rural development non governmental organizations, which are considered in this paper as one of the pillars of an alternative rural development proposal.
\end{abstract}

Keywords: rural development, local development, institutions, participation, rural poverty.

\section{Resumen}

El objetivo de este artículo es contextuar y analizar la situación del desarrollo rural en la Argentina. De manera particular, interesa indagar las capacidades de los distintos programas existentes de desarrollo rural para promover una transformación del sector, en un contexto de carencia de recursos y debilidades institucionales, nacionales, provinciales y locales. En el primer apartado se adelanta nuestra perspectiva sobre las condiciones de viabilidad para el desarrollo rural en el presente. A continuación se elabora un diagnóstico sobre las actuales características del desarrollo rural en el ámbito nacional y su situación institucional. Finalmente, en el tercer apartado se analizan las acciones de las organizaciones no gubernamentales de desarrollo rural, consideradas en este artículo como otro de los pilares de una propuesta de desarrollo rural alternativo.

Palabras clave: desarrollo rural, desarrollo local, instituciones, participación, pobreza rural.

\footnotetext{
*Universidad de Buenos Aires. Correo-e: postmaster@manzan.ba.ar
} 
1. La transformación institucional y el desarrollo local como condiciones del desarrollo rural ${ }^{1}$

\subsection{Reestructuración del Estado y de las instituciones}

La crisis terminal por la que está pasando Argentina obliga a repensar el funcionamiento de la democracia, y como señala Rosanvallon, avanzar hacia una nueva era de lo social, pero también de lo político (Rosanvallon, 1995: 11 y ss., 27 y ss.). Esto nos lleva a renovar la visión y el rol del Estado, e indagar especialmente su interacción con la sociedad civil y con el sector empresario y productor.

En el actual estadio del proceso de acumulación, la crisis de la filosofía del Estado Benefactor desarticuló la lógica social y espacial previa, comenzando a delinearse un Estado con particularidades diferentes al Estado de Bienestar. Desde la perspectiva neoliberal aparecen propuestas y acciones dirigidas a promover un Estado más pequeño y supuestamente más eficiente (dependiendo para quién y para qué), con delegación de funciones hacia provincias y municipios y, especialmente, con una mayor participación de la sociedad civil a través de sus diferentes organizaciones. Muchas acciones, antes responsabilidad del Estado nacional, han sido transferidas en el presente a los estados provinciales, municipales y aun a organizaciones no gubernamentales (ONG). Se trata de un proceso descentralizador, a veces de funciones pero no de recursos. Y por ello y por la ausencia de programación y capacitación (que hubiera requerido esta transformación del sector público) ha resultado generalmente limitado (e incluso negativo) en sus efectos para el desarrollo socioeconómico nacional, regional y local. Este nuevo tipo de Estado, en el que asumen un rol importante no sólo la nación, sino también las provincias, los municipios y la sociedad civil, Oszlak (2001) lo denomina "Estado transversal”.

Desde esta nueva realidad observamos potencialidades que pueden aprovecharse desde otra perspectiva política: aquella que atienda a los sectores populares más desprotegidos y desfavorecidos por la acción de la política neoliberal. Es entonces posible transformar al Estado, haciéndolo más participativo y solidario

${ }^{1}$ Este artículo forma parte de una investigación dirigida por la autora y referida a los Programas de Desarrollo Rural en la Argentina, y que ha contado con el apoyo financiero del Consejo Nacional de Investigaciones Científicas y Tecnológicas (CONICET) y de la Universidad de Buenos Aires, Argentina. 
con los sectores de menores recursos, desocupados, productores, pequeñas y medianas empresas. Vemos fuerzas que abren ámbitos de acción tanto en lo político como en lo económico. Entre ellas la posibilidad de:

i. Gestar un nuevo polo de poder en condiciones de enfrentar al verdadero beneficiario de la globalización y la integración regional: la élite del capital más concentrado resultante de los nuevos procesos de acumulación. La participación y gestión de los beneficiarios puede conformar una valla de contención para los procesos negociados entre el sector público y privado y, en general, para todas las acciones burocráticas, fraudulentas o corruptas.

ii. Refundar la solidaridad social y política a través de las formas asociativas y las redes. A partir de ellas se podrán reconstruir los derechos ciudadanos, identificar las nuevas reglas de convivencia, de justicia, y de gestión social y económica.

iii. Fomentar políticas de crecimiento del producto y de la productividad y de redistribución de ingresos como opción a las políticas de ajuste, equilibrio fiscal y concentración económica. Para avanzar hacia una reducción de la polarización social, de la enorme brecha entre los sectores de mayores y menores ingresos, el camino es el aumento de la producción, de la productividad y la redistribución del producto resultante, en favor de los sectores postergados por el modelo de ajuste. Lo anterior obliga a mantener el control del crecimiento de tal manera que no conlleve mayor concentración económica y, para ello, es necesario dirigirlo a través de instrumentos de política fiscal y de control social. ${ }^{2}$ Un modelo más equitativo y de mejor distribución no sólo permitirá la inserción plena de los sectores marginados, desocupados y excluidos en el aparato productivo nacional, sino también facilitará la gestación de un proceso de crecimiento acumulativo.

Entonces, la actual viabilidad de un desarrollo nacional y regional ya hace tiempo que no queda en las manos de un 'Estado de Bienestar' que opera desde la expansión del gasto fiscal. Aquél fue sustituido por el Estado 'mínimo', a través de la reducción 
del sector público, el avance del sector más concentrado del capital y de los organismos internacionales en la gestión de la política pública, además de las limitaciones operadas sobre la soberanía nacional (y más aún en países del tercer mundo). Ahora se sostiene, desde la misma visión neoliberal, que el 'desarrollo' depende cada vez más de la interacción continua y permanente entre la acción del Estado (en sus diferentes ámbitos: nacional, provincial y municipal, y desde sus organismos de gestión, investigación, salud, educación) con el sector empresario (grandes, medianas y pequeñas empresas, productores independientes -en ambos casos, ya sea en el ámbito de la producción o de los servicios-) y las organizaciones cooperativas y solidarias (ONG, asociaciones religiosas, cooperativas, cooperadoras, gremios, sindicatos).

Sin embargo, desde una visión alternativa en favor de las mayorías marginadas del modelo neoliberal, también creemos que esta 'interacción' vertical y horizontal entre sector público, empresas y sociedad civil puede posibilitar el 'desarrollo'. Se trata también de redefinir lo público y al Estado mismo. Pero para ello la transformación institucional o las nuevas o renovadas instituciones en todos los ámbitos (públicos y privados) es una condición sine qua non. Instituciones que promuevan una acción transparente, solidaria y participativa es el punto de partida para promover un mejor desempeño económico nacional que permita salir de la crisis y avanzar hacia el crecimiento productivo de largo plazo (véase North, 1995: 25 y ss.). Esto significa demoler la estructura institucional que fue funcional a las privatizaciones, la mayor fuente de los recursos que sostuvieron la corrupción, las prebendas y el clientelismo políticos.

Un nuevo modelo institucional exige la aplicación regular, generalizada y democrática de normas y leyes, de gestión y ejecución transparentes y resultantes de la participación de las mayorías, hoy excluidas de la discusión política y pública (North, 1995: 21 y ss.). Y esto promueve el logro de eficiencia y efectividad en el desempeño económico, hoy inexistente, que se traduce en beneficios e ingresos provenientes de incrementos productivos y de mejoras tecnológicas y no del amiguismo, del apoyo partidario, o de las prácticas corruptas o mafiosas.

Un nuevo modelo institucional exige tomar conciencia sobre las limitaciones del anterior. Porque sólo una vez que se ha reconocido la ilegitimidad institucional del presente, es posible avanzar en la construcción de un sendero de transformación fundado en la experiencia, el conocimiento idóneo, el aprendizaje, 
las prácticas burocráticas basadas en la ética, la austeridad y la transparencia. Pero este objetivo no puede lograrse si no es en un contexto de búsqueda de consenso y acuerdo entre las grandes mayorías para compatibilizar intereses y dirimir conflictos ante la opinión de la mayoría, o ante el dictamen del conocimiento experto en numerosas decisiones (aunque sean perjudiciales para algunos -véase Brett, 1999a: 27-).

\subsection{El desarrollo rural como elemento del desarrollo local}

Un nuevo modelo institucional, una redefinición de lo público comienza por este ámbito en sus diferentes expresiones: nacional, provincial y municipal. Y la interacción con la sociedad civil y con las empresas se dará en todos estos niveles. Sin embargo, es en el ámbito de lo local donde existe más viabilidad para que la población se involucre en la gestión y transformación de su propia realidad. Precisamente en el ámbito local se resumen varias de las claves para hacer posible un desarrollo alternativo como el que aquí se está postulando; en palabras de Boscherini y Poma (2000: 34) en el ámbito de lo local:

...el Estado puede recuperar su rol activo y positivo a través del diseño y de la implementación de políticas 'desde abajo' (bottom up) que involucren a los agentes económicos y sociales territoriales, directa e indirectamente interesados en los procesos de desarrollo local y que son los reales destinatarios de las políticas. Estas acciones se caracterizan por una profunda interrelación entre los planes estatales y privados nacionales y locales, requieren importantes procesos de cambio de los agentes y de las instituciones involucradas, y apuntan a regenerar las relaciones en la sociedad civil, estimulando la participación de los agentes y de las instituciones políticas, económicas y sociales (cursiva nuestra).

Pero, además, en el ámbito de lo local los gobiernos tienen un rol reconocido en el actual contexto de globalización. En palabras de Borja y Castells (1998: 17):

los gobiernos locales adquieren un papel político revitalizado en consonancia con la crisis estructural de competencias y poder con que se encuentran los estados nacionales en el nuevo sistema global.

Aquí es, entonces, donde aparece más claramente conectado el desarrollo rural con el desarrollo local, y con el ámbito espacial, político y administrativo de pertenencia. Pero esta conexión aparece también con relación a la gestión del desarrollo económico. Promover políticas y acciones de desarrollo rural demanda una mirada que incorpore a la región y al ámbito local de referencia, 
que visualice interacciones, posibilidades y debilidades con dicha región y con la comunidad y/o municipio respectivo. Si la comunidad local pasa por procesos de auge o declinación económica, la actividad en el ámbito rural no puede menos que ser impactada. Del mismo modo, ambas son afectadas y dependen del tipo de políticas, acciones y medidas micro o macroeconómicas determinadas, sea desde la nación, las provincias e incluso desde los municipios (Manzanal, 1998: 74).

Pero además, sólo desde su inserción en lo local-regional, lo rural podrá posicionarse frente al proceso de globalización. Se trata de una articulación necesaria que en términos de Borja y Castells (1998: 329) se denomina "glocalización" (articulación de lo global y lo local). Estos autores sostienen que sólo desde lo local, desde el 'lugar', es posible hacer énfasis en:

el papel gestor-coordinador-promotor de los gobiernos locales para la implementación de políticas que tienen en cuenta unos referentes globales y se posicionan respecto a ellos. En síntesis globalización más proximidad (cursiva nuestra).

La articulación (y al mismo tiempo el enfrentamiento) entre el espacio de 'los lugares', 'de la organización de la cotidianeidad' y el espacio de 'lo global', de la dominación del gran capital, de las redes de flujos, de las estructuras supraestatales es una exigencia del mundo globalizado del presente. Y ello conlleva a que el desarrollo rural sea parte integrante del desarrollo local o microrregional respectivo. Sin embargo, todas estas son razones que tienen que ver con la inserción en el modelo neoliberal, concentrador y excluyente.

Sin embargo, adoptando la postura de Coraggio (1997: 73) quien sostiene que es necesario cabalgar sobre estas fuerzas globalizadoras "para redirigirlas y cambiar cualitativa y cuantitativamente sus resultados”, consideramos que más allá de la articulación local-global, la inserción de lo rural en lo local es una acción transformadora por:

i) Sus impactos políticos: el ámbito de lo local es el territorio de referencia inmediato de la población, donde trabaja y consume, donde ejerce sus derechos y obligaciones, donde participa, se organiza y se capacita en la praxis cotidiana, donde, en definitiva, puede avanzar con acciones que transformen su propia realidad, incluso dirigiéndose a alcanzar la autogestión política y administrativa de su comunidad.

ii) Sus impactos productivos: es indiscutible que la realidad de las familias pequeño-productoras rurales es la interacción 
cotidiana o frecuente (para consumir servicios o para trabajar) con su comunidad, con la población del centro de servicios inmediato, o con la realidad del ámbito local, donde hay capacidades, recursos y ofertas (laborales, de insumos y de productos) que no son únicamente agropecuarias. No se trata de trabajar sólo con la familia rural pobre, ni para el área rural, sino sumar otros actores locales y regionales. Por ello, proponemos una visión que relaciona la problemática macro y micro, para la cual las mejoras ciertas y autosostenidas del nivel de vida de la familia pequeño-productora agropecuaria dependen tanto de las propuestas surgidas participativamente desde cada familia y cada grupo, como de las posibilidades productivas y laborales existentes en el medio local (que es algo más que el ámbito espacial inmediato de referencia).

iii) Sus impactos territoriales: el ámbito local es el territorio donde se conjugan y pueden potenciar la mayor parte de las interacciones cotidianas o frecuentes (de carácter productivo, económico, social o político) entre las familias pequeño-productoras beneficiarias de programas de desarrollo rural con otros productores, empresarios y comerciantes, técnicos, funcionarios públicos y privados (de bancos, comercializadoras, etcétera), docentes e investigadores.

Desde el territorio, desde lo local, es posible promover la conformación de una malla de redes de contacto frecuente con relación a la actividad productiva (y no sólo productiva). Y esto se da a través de la relación cara a cara, o a través de sistemas de comunicación; es lo que Gilly y Torre (2000: 259 y ss.) denominan "proximidad geográfica” y "proximidad organizacional”, respectivamente.

Cuando estas interacciones se vuelven más frecuentes y regulares, se están dando las condiciones para producir un vuelco transformador en el proceso de desarrollo local, más aún cuando involucran al sector pequeño-productor. Se trata de favorecer la creación de fuertes interacciones locales, o una 'atmósfera territorial', o ámbitos espaciales con dinámica y crecimiento productivo y económico, motorizados por el aprendizaje, la capacitación, la innovación necesaria para ampliar la producción y el mercado local y regional, e incluso alcanzar el mercado global (Poma: 2000: 392 y ss.). Esto ocurre a partir de la conformación de redes de vinculación entre el sector público, la sociedad civil y 
las empresas (Brett, 1999a: 32 y ss.), y en las cuales la participación de la población organizada controla y resguarda los intereses de la mayoría de la población y de las pequeñas y medianas empresas, ya que siempre está el riesgo latente de que estos procesos sean absorbidos y dominados por las grandes empresas nacionales y transnacionales.

\subsection{El rol de la participación de la población organizada desde sus bases}

Es a partir de la participación de la población organizada como se asegura que el proceso de interacción entre instituciones locales favorezca a la mayoría de la población y a las pequeñas y medianas empresas, y no derive en formas de polarización o concentración del capital.

De todos modos, hoy en día el tema de la participación suena deslucido, en tanto que también es usado para justificar la propuesta neoliberal de achicar al Estado, disminuir el gasto fiscal y descentralizar sus obligaciones en materia de política social. ${ }^{3}$ Por participación entendemos no una mera forma declamativa, sino un proceso paulatino de avance en la toma de decisiones de los sectores populares organizados (en organizaciones representativas de base) y en las materias que le competen (relacionadas con su trabajo, sus condiciones de vida, su comunidad).

Por otra parte, el paso siguiente es alcanzar la institucionalización de la participación para garantizar la presencia de las mayorías en las decisiones de gestión local, o en otras palabras: en la autogestión del desarrollo local.

Desde esta perspectiva, la participación es un proceso dialéctico en continua transformación, a partir del cual la población organizada avanza permanentemente (con las respectivas contradicciones de todo proceso social) hacia la conquista de espacios institucionales de decisión y, de este modo modifica el curso de las decisiones de otros sectores, siendo su objetivo hacer viable otro tipo de desarrollo local, redistributivo y con mejoras en las condiciones de vida. Del mismo modo, postulamos la institucionalización de la capacitación y de la organización de los sectores populares.

${ }^{3}$ En Brett (1999b: 5 ss.) aparece un análisis sobre las diferentes formas de participación, sus posibilidades y límites teóricos y prácticos. Se centra en las que denomina sus dos expresiones extremas: la "fuerte" (control directo) y la "débil" (manipulada por las agencias). 
La participación, la capacitación y la organización son variables interrelacionadas y que se retroalimentan; son partes de una misma unidad que construye los procesos de democratización de la gestión pública.

Esta interdependencia se expresa en el dicho de que no hay participación sin organización. Nos referimos a una organización social representativa del conjunto de intereses particulares de un mismo sector social, que exprese demandas generales y no particulares, que preocupen al conjunto y, asimismo, aumente su poder social de negociación. Por ejemplo, en el caso de los pequeños productores agropecuarios, sus organizaciones de base representan los intereses del conjunto de pequeños productores y que se pueden ir ampliando en la medida en que se agregan territorialmente (empezando por un grupo asociado por su cercanía física, ámbito o localidad, para luego sumarse a sus pares de un departamento, o una provincia determinada). No se trata de diferenciar por sectores productivos, que sería una forma de dividir sus fuerzas e intereses. Precisamente, las organizaciones por sector productivo o tipo de actividad son las que han sido utilizadas por muchos gobiernos provinciales para atomizar la demanda de los pequeños productores como grupo con demandas propias.

Al mismo tiempo, es a partir de las organizaciones como es posible profundizar la participación ciudadana, dejando de lado problemas particulares que dividen en vez de sumar fuerzas. Y en el mismo sentido, esta población organizada tiene que avanzar en su capacitación en diversas áreas y temáticas, en forma permanente, para que efectivamente sea posible dirigirse hacia la autogestión local y el control social. Para asumir un rol y un compromiso de acción política, inédito hasta el presente, la capacitación es crucial en temas y áreas que se irán configurando a partir de las demandas que la propia praxis de organización y participación reclame y determine.

Si bien la estabilidad democrática es una condición, es sabido que ella se fortalece y consolida con la plena participación de la mayorías como protagonistas de su propio desarrollo (Coraggio, 1997: 83). Se trata de "impulsar sin ambigüedades la participación extendida de la población en la discusión y resolución de los problemas nacionales, sectoriales y regionales [...] encarar el desafío cotidiano de dirigentes dispuestos a dar la 'cara al pueblo"” (Coraggio, 1997: 25, cursiva nuestra). Es necesario internalizar y comprender que este es el único modo de vencer los 
movimientos de tipo reivindicativo y la mercantilización de la política y dirigirse hacia una revalorización de lo político y lo cultural.

\subsection{Hacia la redefinición de la política y la autogestión del desa- rrollo local}

Todo lo anterior está dirigido a potenciar la economía local y la producción. Pero hay otra faceta, aún más decisiva: la política, o dicho de otro modo, el accionar participativo de la población con el objetivo de alcanzar en algún momento la autogestión del desarrollo local. Los aumentos en la producción no se expresarán en mejoras en la distribución del ingreso local, a menos que los sectores locales ejerzan su derecho a la participación política y a la descentralización democrática de las organizaciones locales. Sólo una renovación institucional general (comenzando por los ámbitos públicos) puede generar las condiciones para avanzar hacia mejores condiciones de vida, locales, regionales y nacionales.

La tarea de readecuación (o reingeniería) tanto de los programas de desarrollo rural como de las distintas instituciones locales y provinciales (públicas y privadas) es un proceso que se hace a partir de la participación, la concientización y la capacitación de la población. Conjuntamente, se irá construyendo otro modelo de desarrollo local y regional: un modelo participativo, transparente, e integrador de las mayorías marginadas. En otras palabras, que supere el contexto territorial, institucional, político y socioeconómico del presente, inviable para el desarrollo local o regional. La transición no es, de ningún modo, automática; tampoco es sencilla. Conjuntamente, nuevos instrumentos de gestión (públicos y privados) deberán irse introduciendo, con un estricto control social, para producir dicha transformación.

Es en esta transición cuando se torna estratégica la función de la política, a partir de un nuevo modo de ejercerla. Se trata de redefinir la política a partir de la participación de la población y a través de sus organizaciones representativas. Esto se da en un proceso continuo y creciente de adquisición de habilidades (capacitación) para transitar el camino desde el control de la gestión local hasta alcanzar la autogestión.

Entonces, resignificar la política es generar un modelo centrado en la democracia participativa, que premie la ética y la transparencia, y controle, sancione y excluya a quienes se apartan de la misma y desconozcan sus promesas eleccionarias. Y para ello 
se necesita intensificar la acción política (y no disminuirla o limitarla) para que la mayoría pueda conquistar mayores niveles de educación, que le permitan intervenir en la autogestión y el desenvolvimiento de sus propios ámbitos de acción (locales, territoriales e institucionales).

Todo esto significa, además, asumir que se trata de un proceso donde la población en su conjunto está comprometida, donde no hay soluciones individuales sino del conjunto, donde el objetivo está puesto en la transformación estructural. Implica, asimismo, adoptar una perspectiva regional, histórica y de mediano plazo (y aun de largo plazo), ya que ningún desarrollo es posible en el marco limitado de un grupo de familias, un territorio o de una coyuntura particular.

De todos modos, tampoco pueden desconocerse las urgencias, la necesidad de afrontar situaciones de corto plazo, las demandas de asistencia para los más carenciados, o las soluciones de problemas impostergables. Dentro del modelo que postulamos, afrontar la solución a necesidades inmediatas es parte del mismo proceso participativo de transformación institucional: es parte de la praxis cotidiana. El accionar conjunto, solidario y a través de las respectivas organizaciones irá solucionando, afrontando y, en definitiva, construyendo otra realidad más compartida y menos individual.

\section{El Estado nacional y su acción ante el desarrollo rural}

En Argentina, los programas dirigidos a los pobres rurales se gestaron en el contexto del ortodoxo ajuste neoliberal, con una polarización social creciente y con un Estado prescindente y carente de instrumentos para la implantación de una política de desarrollo nacional. Una parte importante de estos programas se basaron en la transformación productiva y en el mejoramiento de los ingresos o del nivel de vida de los pobres rurales, en general, pequeños productores agropecuarios (PP). Ya avanzados los años 90 se dirigieron, también, a trabajadores transitorios agropecuarios (TTA). Sin embargo, estas propuestas resultan contradictorias con la política macroeconómica, generadora de crecientes procesos de marginación o exclusión social, y en particular del sector pequeño-productor agropecuario (Manzanal, 2000: 80).

En realidad, no ha existido un diagnóstico general en el ámbito nacional sobre la población rural pobre; tampoco una 'estrategia de desarrollo rural' definida. Lo que existe es un con- 
junto de programas, cada uno con sus diagnósticos en distinto grado de realización, sus objetivos e instrumentos, a través de los cuales se puede deducir, por la presencia de ciertas regularidades, una estrategia general común.

De esta suma de acciones para pobres rurales, las más importantes en alcance y monto y en su carácter integral surgieron desde el Estado nacional. También algunas provincias tienen propuestas propias, aunque mucho más acotadas. Lo mismo sucede con las ONG (Manzanal, 2000: 88-93). Hay pocas ONG con una larga experiencia de intervención con el sector pobre de pequeños productores rurales.

Los principales programas nacionales, vigentes en el presente y con una estrategia dirigida a mejorar las condiciones de vida a partir de la asistencia técnica, subsidios y créditos, se gestaron en la órbita de la Secretaría de Agricultura, Ganadería, Pesca y Alimentación de la Nación (SAGPYA). Dichos programas son:

a) PRODERnEa: Programa de Desarrollo Rural del Noreste Argentino, iniciado en enero de 1999 (es continuación del PPNEA -Programa de Pequeños Productores del Noreste Argentino-, finalizado en 1997). La población meta ${ }^{4}$ es de 42 mil familias con explotaciones menores a las 25 ha en $\mathrm{Mi}$ siones, Corrientes, Formosa y Chaco, y 10,500 familias aborígenes en Misiones, Chaco y Formosa. Es un proyecto por cinco años, por un monto de 36 millones de dólares. ${ }^{5}$

b) PSA: Programa Social Agropecuario, iniciado en 1993, con un universo o población objetivo cercano a las $160 \mathrm{mil} \mathrm{fa-}$ milias minifundistas localizadas en todas las provincias, con excepción de Tierra del Fuego y Santa Cruz (no tiene población meta). Su financiamiento ha estado sujeto a partidas presupuestarias del orden de 9 millones de dólares anuales, en promedio.

c) PRoINDER: Proyecto de Desarrollo de Pequeños Productores Agropecuarios (ampliación del PSA), iniciado en agosto de

${ }^{4}$ En general, los programas distinguen entre población meta (la que efectivamente atenderán) y población objetivo (el universo de personas con una situación socioeconómica similar a los beneficiarios respectivos).

${ }^{5}$ Todas las cifras en dólares o pesos argentinos que se exponen corresponden al periodo de la convertibilidad (que terminó en enero de 2002). Durante dicho periodo, que se extendió por más de diez años, un dólar era igual a un peso argentino. ¿Cuáles son esos recursos después de la convertibilidad? Es una cuestión que en el presente pasa por muchas ambigüedades, porque el dólar ha superado los 3 pesos y porque la incertidumbre es creciente en un país donde, empezando por el Estado, las empresas y el sector financiero se desconocieron y rompieron los acuerdos y contratos privados y públicos. 
1998, con un universo o población objetivo cercano a las 130 mil familias con necesidades básicas insatisfechas, vinculadas a la producción agropecuaria y localizadas en todo el país, menos Tierra del Fuego y Santa Cruz (la población meta es de 40 mil pP y TTA). Su duración es de cinco años y el monto total de financiamiento es de 100 millones de dólares.

d) PRODERnOA: Programa de Desarrollo Rural del Noroeste Argentino, aún en gestión. Aportará asistencia técnica y financiera a 6 mil familias de pequeños productores de las provincias de Salta, Catamarca y Jujuy. Es un proyecto para cinco años, por 25 millones de dólares, con aportes del International Fund for Agricultural Development (FIDA, en español).

Otros programas con acciones más particularizadas, pero que también operan desde la SAgPYA son: Cambio Rural, Unidad de Minifundio, Pro-Huerta, Proyecto de Reordenamiento de Áreas Tabacaleras (PRAT), Proyecto Forestal de Desarrollo (CAPPCA), Régimen de Promoción de Plantaciones Forestales (RPPF), Programa de Asistencia Subsidiada a Productores Ganaderos Minifundistas de la Patagonia (PROSUB). Éstos se diferencian de los antes mencionados porque, en general, carecen de una estrategia integral para la transformación de los pequeños productores, o su componente principal es la asistencia técnica, más que el crédito o el subsidio, o tienen una definición más general de la población objetivo, o sólo participan con algún componente específico para pequeños productores en el marco de acciones más amplias (Manzanal, 2000: 88). También la SAGPYA trabaja con programas de emergencia que atienden, entre otros, a pequeños productores. Es el caso del Programa de Apoyo a la Producción Agropecuaria Patagónica en Emergencia, creado en 1996 para revertir los efectos de fenómenos climáticos adversos sucedidos en la Patagonia en $1995 .^{6}$ Hay además otras áreas del sector público nacional con programas que llegan con sus beneficios y acciones hasta los pequeños productores. Es el caso de la Secretaría de Desarrollo Social de la Presidencia, con el Fondo Participativo de Inversión Social (FOPAR) y el de Capitalización (FONCAP); del Ministerio de Trabajo

\footnotetext{
${ }^{6}$ Otro caso fue el proemer (Proyecto de Recuperación de la Capacidad Productiva de los Pequeños Productores Agropecuarios, afectados por las inundaciones de 1999 en el noreste argentino).
} 
con el Proyecto Joven, el Plan Trabajar y el Forestar y el de Microemprendimientos del Consejo Federal de Inversiones (CFI).

Todos son relevantes, precisamente, por las potencialidades que tratados en conjunto y coordinadamente tendrían para transformar al pequeño sector productor agropecuario. Pero esto no sucede. Precisamente, esta enunciación da cuenta, por sí sola, de la ausencia de una política, de una estrategia coordinada que fortalecería la acción institucional con el sector pobre del agro.

Esta falta de coordinación entre los programas se observa también en el ámbito del modelo institucional de cada uno de ellos en el siguiente cuadro (véase el cuadro 1).

En los casos expuestos en el cuadro 1, la institución nacional responsable es el Instituto Nacional de Tecnología Agropecuaria (INTA) o la Secretaría de Agricultura, Ganadería, Pesca y Alimentación (SAGPYA). Las mayores diferencias aparecen con la unidad ejecutora, mostrando distintos grados de centralizacióndescentralización. Los más centralizados son aquellos en los cuales la unidad responsable y la ejecutora coinciden (Cambio Rural, Unidad de Minifundio, Pro-Huerta, PSA, PROINDER, CAPPCA, RPPF ${ }^{7}$ ). Y en los más descentralizados, la unidad ejecutora son las provincias (como el PRODERNEA y PRAT). De este conjunto de nueve programas, hay sólo tres cuyo financiamiento proviene de fuentes internacionales (PROINDER, PRODERNEA Y CAPPCA).

Como se aprecia, el desarrollo rural aparece como una suma de programas y no como una estrategia nacional. Además, por las instituciones involucradas, se observa que está claramente circunscrito a la cuestión rural; el desarrollo local y el rol de los municipios es una materia ausente.

Esta diversidad de programas condujo, en marzo de 1999, a la creación de la Comisión de Desarrollo Rural de la SAGPYA, integrada por un representante de cada programa mencionado. Sin embargo, dicha Comisión no tiene capacidad de decidir sobre la ejecución individual de cada programa. Por ello surge la pregunta: ¿cuánta voluntad de coordinación hay cuando la organización institucional de cada programa es distinta? Así en el PRODERNEA cada provincia tiene un rol muy importante en la fijación de la estrategia, mientras que en el PSA y Cambio Rural lo tiene la nación, mientras que para el INTA lo relevante son los consejos regionales.

\footnotetext{
${ }^{7}$ En este programa los municipios identifican a los beneficiarios, pero el proyecto y el financiamiento se aprueba y maneja desde la SAGPYA.
} 


\section{Cuadro 1 \\ Programas nacionales de desarrollo rural: beneficiarios, instituciones públicas participantes y montos de asistencia financiera, año 2000}

\begin{tabular}{|c|c|c|c|}
\hline $\begin{array}{l}\text { Denominación del } \\
\text { Programa / } \\
\text { Beneficiarios } \\
\text { Año 2000 }\end{array}$ & $\begin{array}{l}\text { Institución } \\
\text { responsable }\end{array}$ & $\begin{array}{l}\text { Institución } \\
\text { ejecutora }\end{array}$ & $\begin{array}{l}\text { Monto de asistencia financiera } \\
\text { a beneficiarios, año } 2000 \\
\text { Inst. financiadora y porcentaje } \\
\text { de financiación }\end{array}$ \\
\hline $\begin{array}{l}\text { Cambio rural } 14,336 \\
\text { productores, organizados } \\
\text { en } 1,509 \text { grupos }\end{array}$ & INTA & INTA & $\begin{array}{l}\text { No corresponde / } \\
\text { Gobierno nacional (SAGPYA) }\end{array}$ \\
\hline $\begin{array}{l}\text { Unidad minifundio } \\
17,410 \text { productores }\end{array}$ & INTA & INTA & $\begin{array}{l}\text { No corresponde / } \\
\text { Gobierno nacional (SAGPYA) }\end{array}$ \\
\hline $\begin{array}{l}\text { Pro-Huerta 2'478,500 } \\
\text { personas; } 384,400 \text { huertas } \\
\text { y granjas }\left({ }^{1}\right)\end{array}$ & INTA & INTA & $\begin{array}{l}\text { No corresponde / } \\
\text { Gobierno Nacional (Secretaría } \\
\text { de Desarrollo Social) }\end{array}$ \\
\hline $\begin{array}{l}\text { PSA } \\
15,500 \text { familias (sólo } \\
\text { asistencia técnica) } \\
\text { 2,086 familias (créditos) }\end{array}$ & SAGPYA & SAGPYA & $\begin{array}{l}\$ 785,000\left(^{2}\right) \\
\text { Gobierno nacional (SAGPYA) }\end{array}$ \\
\hline $\begin{array}{l}\text { PROINDER } \\
8,700 \text { familias }\end{array}$ & SAGPYA & SAGPYA & $\begin{array}{l}\$ 4 ' 505,231 \\
75 \% \text { BIRF } \\
25 \% \text { Gobierno nacional }\end{array}$ \\
\hline $\begin{array}{l}\text { PRODERNEA } \\
303 \text { familias }\end{array}$ & SAGPYA & $\begin{array}{l}\text { SAGPYA y } \\
\text { Ministerios de } \\
\text { Asuntos Agrarios de } \\
\text { las Provincias }\end{array}$ & $\begin{array}{l}\$ 670,000 \\
45.7 \% \text { FIDA } \\
52.6 \% \text { Provincias } \\
1.6 \% \text { SAGPYA }\end{array}$ \\
\hline $\begin{array}{l}\text { CAPPCA } \\
413 \text { familias (donaciones); } \\
187 \text { familias (sólo } \\
\text { asistencia técnica) }\end{array}$ & SAGPYA & SAGPYA & $\begin{array}{l}293,957 \\
52.6 \% \text { BIRF } \\
47.4 \% \text { SAGPYA }\end{array}$ \\
\hline $\begin{array}{l}\text { RPPF / 4,157 }\left({ }^{4}\right) \\
\text { Planes individuales: } 256 \\
\text { productores; } \\
\text { Planes grupales: s.d. } \\
\text { productores; } 66 \\
\text { municipios; } \\
\text { Proyectos agrupados: } 276 \\
\text { productores }\end{array}$ & SAGPYA & $\begin{array}{l}\text { SAGPYA y provincias. } \\
\text { SAGPYA y provincias } \\
\text { SAGPYA }\end{array}$ & $\begin{array}{l}\$ 495,241 \\
\$ 950,000\end{array}$ \\
\hline $\begin{array}{l}\text { PRAT } \\
19,919 \text { productores } \\
\text { tabacaleros }\left({ }^{5}\right)\end{array}$ & SAGPYA & $\begin{array}{l}\text { Unidades } \\
\text { provinciales }\end{array}$ & $\begin{array}{l}15^{\prime} 635,692\left(^{3}\right) / \\
\text { Sujeto a la recaudación por } \\
\text { venta de cigarrillos }\end{array}$ \\
\hline
\end{tabular}

Fuentes: SAGPYA (2000) y PROINDER (1999).

Notas: (1) Los beneficiarios de este programa son familias NBI urbanas y rurales. Del total de beneficiarios que aquí figuran, en el año 1998 se calcularon que 40 mil eran Pp. (2) El PSA tuvo en años anteriores mayores partidas de apoyo financiero que en el 2000: la asistencia financiera acumulada desde abril de 1993 al 31 de diciembre de 1999 fue de us\$ \$30’317,075. (3) El CAPPCA del Proyecto Forestal comenzó en 1998. El monto total para el componente CAPPCA es $\$ 5^{\prime} 484,000$ en cinco años. Se trata de asistencia técnica y financiera no reintegrable para proyectos forestales en Neuquén, Salta, Chaco, Formosa y Misiones. (4) El RPPF no tiene población objetivo, ni meta; el monto total está sujeto a partidas presupuestarias y los proyectos individuales comenzaron en 1992, los grupales en 1993 y los agrupados en 1997. La prestación a los beneficiarios es apoyo financiero no reintegrable para forestación, y tiene cobertura nacional en áreas edafoclimáticas apropiadas. (5) Corresponde al año 1999, y se dirige al conjunto de productores tabacaleros no exclusivamente a PP. Se da asistencia técnica, en infraestructura y financiera no reintegrable para reconversión. 
Este contexto alimenta las siguientes dudas: ces posible que los técnicos provinciales logren en terreno lo que no se logra en el ámbito central de decisión?, ¿̇si no hay acuerdos en el ámbito gerencial, pueden los técnicos organizar su trabajo de campo y coordinar la acción de los distintos programas? (aquí nuevamente resalta la ausencia del rol del ámbito local o municipal).

Es indudable que no puede coordinarse en terreno si desde la SAGPYA no se opera un acuerdo general de diagnóstico, programación, ejecución y funcionamiento, conjunto y coordinado, de modo que garantice la ausencia de superposición y competencia entre programas y la solidaridad y complementariedad entre ellos. $\mathrm{Y}$ esto significa una organización institucional con capacidad y autoridad para definir el rumbo, es decir, para definir la estrategia de desarrollo rural y ejecutarla. Único modo para que desaparezcan duplicaciones por zonas, o por población beneficiaria, y para lograr la articulación, la cooperación, la eficiencia y la eficacia en el uso de los recursos humanos y físicos, técnicas e instrumentos disponibles y por crearse. Es indudable que tal estrategia no existe.

No existe porque no hay una política de desarrollo rural, porque no ha sido una prioridad para el Estado nacional. El desarrollo rural ha sido sólo una cuestión subsidiaria de la política neoliberal, que ha asumido la necesidad de afrontar algunos problemas sociales desde la óptica de la beneficencia paradisciplinar a los sectores más desposeídos.

Precisamente, en documentos de los propios programas se acepta la carencia de una estrategia para el sector pobre rural. En un documento de PROINDER (1998: 12) se precisa que la estrategia nacional o de la SAGPYA no fue elaborada a priori, ni resultó de un único diagnóstico. Por el contrario, es una consecuencia del conjunto de decisiones "que se fueron tomando en cada programa". Por lo cual tampoco sus objetivos finales están expresamente señalados.

$\mathrm{Al}$ analizar en detalle el material de la SAGPYA sobre desarrollo rural, se observan las siguientes limitaciones:

i. No constituyen una estrategia explícita de la nación, sino que es resultado de estrategias particulares de diferentes programas no coordinados efectivamente entre sí (además no siempre explicitadas);

ii. Se trata de objetivos que son una expresión de metas, pero que no reciben un tratamiento conjunto e integral de articulación y complementación; 
iii. Son objetivos intermedios e instrumentos de acción, cuya concreción difiere notablemente según programas, provincias y ámbitos locales y rurales.

La realidad es que el Estado nacional es -y ha sido- indiferente a la política de desarrollo rural. Acepta ciertas acciones en la medida en que su compromiso con las mismas es menor y las toma como esfuerzos circunscriptos, como paliativos que, de algún modo, sirven además para mostrar que algo se hace en la materia de los pp pobres. Y esta falta de interés también implica que tampoco se preocupe por organizar adecuadamente un modelo de coordinación entre todos ellos. Menos aún de la participación y organización de los productores.

De aquí que si bien algunos de estos programas (PSA, PROINDER, PRODERNA) prevén la participación de los productores en las unidades de decisión provinciales, siguiendo la nueva óptica comentada antes en la función del Estado, los métodos y resultados son disímiles según provincias y tipo de programas. En algunas provincias, por ejemplo Corrientes, se ha dado un proceso dinámico de organización en diferentes niveles de los productores, mientras que en otras esta participación es meramente formal. Incluso, en una misma provincia las situaciones también son diferentes dependiendo de qué programa se esté analizando (caso de la región noreste, donde coinciden varios de ellos). Es decir, el proceso de integrar a los productores en los niveles de decisión, muchas veces impulsado desde los propios organismos internacionales, ha sido muy disparejo en sus resultados (lo cual se reconocerá mejor en el siguiente apartado). Y ello es una muestra más de la poca atención y subsidiariedad con que ha sido tratada la estrategia de desarrollo rural desde el poder político, más bien dirigida a que opere como paliativo en vez de constituir una práctica transformadora.

También nos preguntamos: ¿por qué se implantan programas que atienden de modo diferente a los pequeños productores pobres? En primer lugar, porque la mayor parte de estas acciones sociales son promovidas desde organismos de financiamiento internacional, en parte para apaciguar la conflictividad social resultante del ajuste, y también para aplicar recursos financieros excedentes (otorgando préstamos a estados nacionales o provinciales), ya que ha existido una importante oferta de recursos internacionales dirigida a atender esta cuestión (Manzanal, 2000: 79-80). 
Ya avanzada la década de los 70 (una vez concluida la crisis del petróleo), se desarrolló un mercado financiero con una abundante oferta de capital ("hipertrofia financiera”, según Beinstein, 1999: 136); origen incluso de la deuda externa y una de las causas de su continuo y acelerado incremento. Esta oferta financiera continúa hasta el presente, con los altibajos propios de las sucesivas crisis (o de las depresiones sigilosas o burbujas que explotan generalmente acompañadas de devaluaciones: Japón desde 1991, México en 1995, Tailandia en 1997 y el derrumbe asiático, Corea del Sur en 1998, Brasil y Rusia en 1999 y Argentina en 2001).

En segundo lugar, porque estos programas son mantenidos internamente por distintos intereses particulares, que van desde efectivas preocupaciones sociales, pasando por el aseguramiento de la continuidad de fuentes de trabajo, hasta el oportunismo político, sustentado en el clientelismo. En definitiva, los programas funcionan como 'instituciones', con un funcionamiento regular; una vez instalados, tratan de garantizar su permanencia y continuidad. Y esto es también lo que impide que se produzca una efectiva articulación entre todos los programas existentes, porque ello significaría reasignar espacios de acción y de poder para algunos.

A nuestro entender, en un contexto de democracia participativa con renovación política e institucional, los distintos programas existentes dirigidos a los pequeños productores rurales y trabajadores transitorios deberían consolidarse en un único programa. Habría una única estrategia nacional referida a los objetivos más generales (mejoras en el nivel de vida, inserción productiva, renovación tecnológica, reconversión, etc.) y a los principales instrumentos (crédito, subsidio, asistencia técnica, participación, organización, capacitación, seguimiento y control social participativo, etc.). Y debería quedar bajo la órbita provincial la definición de la estrategia operativa, para que se adecue a cada realidad, mientras que sería el nivel local el responsable de la ejecución. En el nivel local, el gobierno municipal sería uno de los actores; los otros serían organizaciones representativas locales (de productores y del ámbito en general de la producción, de la educación, de las asociaciones religiosas, de la asistencia social). Sabemos que esta es una propuesta riesgosa para operar en las actuales condiciones de estructuración del sistema político, dados los altos grados de corrupción y clientelismo actualmente existentes. Pero también sabemos que hay que comenzar a desandar el camino para poder alcanzar la necesaria transformación institucional. 
Entonces, esta propuesta es factible si y sólo si se asegura el efectivo control y seguimiento por parte de las organizaciones representativas de productores y de la población local de la administración y ejecución del programa en cuestión. Las áreas de control $y$ seguimiento, de premios y castigos son decisivas para avanzar hacia el cambio deseado.

\section{El desarrollo rural en el ámbito provincial: sus instituciones}

Como se ha señalado, las debilidades institucionales de las provincias deben constituir una prioridad en atención del desarrollo rural. Por ello es que en este punto nos ocupamos de identificar si en las provincias existen organizaciones específicas vinculadas con el desarrollo rural, y si están asociadas con la acción de los programas nacionales de desarrollo rural.

Para avanzar en este terreno analítico, utilizaremos como referencia un diagnóstico realizado por la SAGPYA en el que se afirma lo siguiente: "el conocimiento que las provincias tienen de la población objetivo de las políticas de Desarrollo Rural es limitado. Estas limitaciones surgen de la falta de datos actualizados para cuantificar a los pequeños productores y a los trabajadores transitorios agropecuarios, de la escasa relevancia otorgada a la heterogeneidad interna de esa población” (PROINDER, 1999). Esta afirmación surge de observar que:

i. De las 23 provincias, sólo cuatro de ellas (menos de 20\%) han realizado un estudio especial que les permite tener información actualizada sobre el universo de sus PP (Catamarca en 1996-1998, Formosa en 1996, San Luis en 1991 y Tierra del Fuego en 1997).

ii. La estimación de la cantidad de Pp realizada por cada provincia muestra situaciones muy disímiles. Sólo hay seis donde ese cálculo es considerado por la SAGPYA como razonable, en función de una comparación con el análisis de otras fuentes. Los casos restantes reflejan muchas heterogeneidades y en general menor rigurosidad, sea en la forma de estimación o en la definición del sujeto PP.

iii. La identificación de tipos agrarios dentro de los PP es pobre; sólo dos provincias del nordeste (Corrientes y Misiones) avanzaron en el reconocimiento de tipos productivos dominantes, y esto se logró como resultado de la acción en ellas de un programa nacional: el PPNEA, de estructura descentralizada. 
iv. No hay estimaciones de TTA; en el mejor de los casos sólo se dispone de una estimación de su volumen sin ninguna caracterización socioeconómica.

v. La estructura institucional provincial para el desarrollo rural es deficitaria (PROINDER, 1999: 21). Los recursos materiales y humanos son limitados y sólo dos provincias cuentan con un área específica y exclusiva con recursos completos para la atención de los PP. Ellas son: Corrientes (Servicio de Apoyo a Productores -SAP-) y Misiones (Dirección General de Extensión Rural). ${ }^{8}$

vi. Ninguna de las 23 provincias tiene una estrategia provincial de desarrollo rural. Tres (Catamarca, Formosa y Tucumán) dicen tener una estrategia de desarrollo rural, pero en realidad se trata de programas o proyectos de diferente alcance y centrados en la asistencia técnica. Catamarca tiene un Plan Estratégico Consensuado, organizado por programas donde la problemática de los Pp no queda suficientemente diferenciada de la del sector agropecuario general. Por su parte, en Formosa existe el Programa de Atención Integral de los Pequeños Productores Agropecuarios (PAI$\mathrm{PPA})$, que llega a todos los PP de la provincia con insumos (semillas), y a algo menos de un tercio con asistencia técnica. Y finalmente Tucumán, que cuenta con un conjunto de programas y proyectos orientados específicamente a los pequeños productores y en un caso a los minifundistas, pero son en general acciones de asistencia técnica (PROINDER, 1999: 13-16).

vii. En todas las provincias existen organizaciones gremiales con una amplia representación provincial (como es el caso de la Federación Agraria Argentina); en varias hay organizaciones de PP provinciales, cooperativas de PP, cámaras de productores e instituciones de apoyo, como ONG, asociaciones religiosas o universidades. Sin embargo, en la en-

\footnotetext{
${ }^{8}$ Nótese aquí que dos de ellas (Corrientes y Misiones) son provincias que han sido sujetos de un programa nacional de desarrollo rural (PPNEA), que entre 1991 y 1997 fue la base de financiamiento para el sostenimiento de ambas instituciones. Aunque debe señalarse que en Corrientes ya existía el Servicio de Asistencia al Pequeño Productor (SAPP), creado por una ley provincial de 1984 (antes del SAP y también del PPNEA). El SAPP fue, entre 1991 y 1997, la unidad ejecutora del PPNEA (PROINDER, 1999: 7). También hay que reflexionar acerca del hecho de que el SAPP se convirtió en 1998 en el SAP, es decir, dejó de ser una institución volcada exclusivamente a los Pp y desde 1999 atiende también a medianos productores. Con lo cual parece que se estuviera dando una transformación institucional en sentido contrario al fortalecimiento institucional hacia los PP que venimos postulando.
} 
cuesta de la SAGPYA, las provincias muestran un fuerte desconocimiento de las organizaciones que funcionan en sus propios ámbitos. Son pocas las que informan con cierto grado de detalle, entre ellas Catamarca, Corrientes, Misiones, Neuquén, Salta, Santa Fe, Santiago del Estero, Tucumán.

Como se puede concluir, esta información resulta por demás relevante de las dificultades de gestar una estrategia de desarrollo rural nacional con cobertura en las 23 provincias en un contexto de:

i. Notable desactualización de la información sobre pp en el ámbito nacional y provincial;

ii. Diversidad de concepciones sobre el sujeto beneficiario;

iii. Desconocimiento de las características productivas y socioeconómicas de los PP y los TTA;

iv. Ausencia de una estrategia nacional definida en forma centralizada y coordinada y de estrategias provinciales de desarrollo rural;

v. Falta de conexión de las organizaciones e instituciones provinciales que se ocupan del desarrollo rural con las instituciones de PP y de apoyo.

Como vemos, el análisis en el ámbito provincial revela restricciones muy fuertes para implantar una estrategia de desarrollo rural alternativa centrada en los recursos de las instituciones públicas provinciales. Y especialmente queremos destacar que si bien existen organizaciones de productores, éstas no son referentes en varios casos para los funcionarios provinciales. Nos preguntamos: ¿lo serían si se impusiera un sistema de control y seguimiento de sus acciones conformado por una unidad en la que organizaciones representativas tuvieran poder de decisión? Pasemos, entonces, a observar la tercera instancia: el ámbito de lo local.

\section{El ámbito de la participación: algunas realidades locales}

El ámbito de lo local es aquel en donde buscamos encontrar esa 'atmósfera' particular, que haga viable un modelo alternativo para el crecimiento y el desarrollo socioeconómico. Es el 'territorio o lugar' donde es factible visualizar la acción articulada entre el Estado (en sus diferentes instancias: nacional, provincial y municipal), la sociedad civil y el sector empresario (instituciones pú- 
blicas y privadas, organizaciones sociales y gremiales, instituciones educativas y de investigación). Este accionar permitiría conducir un proceso de transformación institucional y de desarrollo productivo general y particular.

Precisamente al analizar el caso particular de los sectores campesinos y pequeños productores, se observa que ellos, en su ámbito espacial de interrelación, demuestran en general una fuerte aptitud para el trabajo solidario y para el intercambio de insumos, productos y mano de obra. Su antigua historia de participación en movimientos cooperativos, locales o regionales, les ha enseñado que la solidaridad y la cooperación es la forma que tienen para poder acceder a bienes y recursos que de otro modo le estarían vedados. Es decir, entre los Pp existe una praxis instalada y una capacidad que potencia las estrategias vinculadas con la promoción de organización del sector.

Sin embargo, y a tono con las carencias institucionales del sector público, en Argentina no hay una presencia significativa de movimientos u organizaciones sociales vinculadas al desarrollo rural, tanto de carácter reivindicativo -gremial, sindicatos, cámaras, uniones, cooperativas-, como de asistencia y promoción-ONG, fundaciones, asociaciones civiles o religiosas. Por ahora, Argentina está lejos de reproducir movimientos sociales rurales con la profundidad y difusión de los que se suceden en otras partes de América Latina (Brasil, por ejemplo, con el de los campesinos sin tierra). Aún así, esta realidad tiene marcadas diferencias de una provincia a otra, incluso entre zonas de una misma provincia, donde juegan un papel decisivo las respectivas historias productivas, identidades culturales y formas de lucha de los movimientos sociales.

El análisis del accionar de las organizaciones rurales del presente debemos enmarcarlo en el contexto de dos efectos disruptores. Uno, la dictadura militar (1976-1983) que buscó la destrucción de las organizaciones y la 'desaparición' o alejamiento de dirigentes y militantes. La persecución a todo pensamiento opositor era el modo de legitimar la ideología del 'proceso' y garantizar la aplicación plena del modelo neoliberal de mediados de los años 70. Otro, el impacto expulsor del empleo y de la actividad productiva del modelo neoliberal, que afectó a amplios sectores de la población (excluidos, desocupados). Es sabido que se viene produciendo una significativa disminución del número de pequeños productores agropecuarios, quienes abandonan o 
venden sus predios y que, por lo tanto, tampoco son parte de los movimientos sociales del sector. ${ }^{9}$

\subsection{Organizaciones de pequeños productores}

Golsberg (1999), en un trabajo en el que analiza el Movimiento Agrario Misionero (MAM) como la única organización de las antiguas Ligas Agrarias ${ }^{10}$ que logró reconstruirse luego de la dictadura, señala un conjunto de causales que explicarían los bajos niveles de participación del presente. Podemos sistematizar dichas causales de la siguiente manera:

i. La represión y su consecuente pérdida de militantes;

ii. La crisis económica, porque exige una mayor cantidad de tiempo para abastecerse de los ingresos mínimos de subsistencia;

iii. La falta de reconocimiento del rol de las organizaciones como un ámbito de resolución de los problemas inmediatos de los pobres rurales, $\mathrm{y}$

iv. La deslegitimación de la participación, producto de la corrupción de los dirigentes políticos en general. A esto nosotros agregaríamos la caída absoluta en el número de pequeños productores ocurrida desde mediados de los 80 hasta la actualidad.

En consecuencia, con la vuelta de la democracia, la reconstrucción y reinstalación de los movimientos sociales agrarios ha sido un proceso muy difícil, lento, y dispar según las realidades locales y regionales. $\mathrm{Y}$ al respecto hay situaciones que resultan paradójicas; por ejemplo, hay organizaciones que se consolidaron, como tales, por vincularse con el Estado nacional o provincial en acciones de desarrollo social (como el MAM; véase Golsberg, 1999)

\footnotetext{
${ }^{9}$ Diversos indicadores e informantes clave señalan una fuerte retracción de la cantidad de pequeños productores en las economías regionales. Vale recordar, además, el escaso interés del sector público por actualizar los datos que revelarían esta situación: el Censo Nacional Agropecuario, que debería haberse relevado en 1998, a 10 años del anterior. Los datos censales disponibles tienen ahora casi 15 años de antigüedad cronológica. Antigüedad mucho mayor si se observa con relación a la profundidad de los cambios ocurridos, ya que la década de los 90 coincide, posiblemente, con la mayor transformación de la economía argentina ocurrida en el lapso de 10 años.

${ }^{10}$ Las Ligas Agrarias es un movimiento organizado en la década de los 70, coincidentemente con el auge de la protesta social en Argentina del periodo 1969-1973. Comenzó en la provincia del Chaco, para luego extenderse a otras provincias y tomar cada vez mayor relevancia social. En sus comienzos surgió representado los intereses de la burguesía agraria nacional enfrentada al capital monopolista en el agro. La dictadura de 1976 persiguió a sus dirigentes y el movimiento fue desarmado.
} 
mientras que a otras les sucedió todo lo contrario. El enfrentamiento con esas mismas políticas consolidó el poder y la representatividad del pequeño sector productor agropecuario (es el caso de la Unión de Pequeños Productores Agropecuarios del Chaco -UN.PE.PRO.CH-; véase Benencia, 1999).

El análisis de la situación y potencialidad de los movimientos sociales de los pequeños productores muestra su organización y sus características en número y tipo de participantes, estructura organizativa y representatividad. Y entre estas organizaciones nos interesan, fundamentalmente, las que representan a los PP en conjunto, y no las organizadas según sector o actividad productiva. ${ }^{11}$

Algunas de las organizaciones de pequeños productores agropecuarios con mayor reconocimiento y presencia (siguiendo, salvo expresa mención, un relevamiento de PROINDER, 1999: 36) son por provincia las siguientes:

- Corrientes: Federación de Asociaciones y Cooperativas de Productores, que engloba a 22 organizaciones de base. Asimismo hay una Asociación Provincial de Pequeños Productores, con mil asociados y 13 asociaciones locales distribuidas en 11 departamentos provinciales (PROINDER, 1999: 35);

- Chaco: Unión de Pequeños Productores del Chaco (Un.Pe.Pro.CH), Asociación de Pequeños Productores del Chaco (A.PE.P.CH.) y la Coordinadora de Tacuruzal (Benencia, 1999: 4);

- Formosa: Movimiento Campesino de Formosa y Movimiento Agrario Formoseño (MAF), que surgió en 1984 con dirigentes de la Unión de Ligas Campesinas de Formosa (Golsberg, 1999);

- Misiones: Movimiento Agrario Misionero (MAM). En esta provincia hay también varias organizaciones de productores por sectores productivos (la de productores de tabaco: APTM, y la de té: APTÉM);

${ }^{11}$ Como ya fue señalado en la primera parte, importa impulsar y reconocer especialmente la acción de las organizaciones de base, y no las organizaciones por sector productivo, o tipo de actividad, utilizadas para atomizar la demanda de los PP como grupo con demandas propias. Las provincias donde las organizaciones de productores funcionan fundamentalmente por sectores productivos son Catamarca (donde existen cámaras y cooperativas de productores nogaleros, citrícolas, cabriteros, pimentoneros, tamberos, orgánicos, con distinto grado de representatividad espacial y productiva) y Tucumán (Liga de Cooperativas Cañeras, Unión de Cañeros Independientes de Tucumán uCIT-, FOTIA, Unión de Tabacaleros de Tucumán, Asociación de Productores de Frutas y Hortalizas). 
- Santiago del Estero: Movimiento Campesino de Santiago del Estero (MOCASE);

- Salta: Asociaciones de Pequeños Productores de La Viña, Cachi y Molinos (UPASSOR en San Martín, Orán y Rivadavia) y organizaciones representativas de intereses aborígenes;

- San Juan: Federación de Cooperativas, de alcance provincial y representa a 11 cooperativas y a 15 grupos pre-cooperativos de PP;

- Chubut y Neuquén: se distinguen por la presencia de organizaciones representativas de aborígenes en defensa de sus identidades y producción.

En 1995, algunas de estas y otras organizaciones decidieron coordinar sus esfuerzos y constituyeron la Mesa Nacional de Organizaciones de Productores Familiares como entidad independiente de los partidos políticos, los gobiernos, las asociaciones religiosas y las ONG, con el fin de tener voz en el ámbito nacional. Representantes de esta mesa han estado participando en distintos foros de discusión de la política sectorial y en diferentes manifestaciones de protesta. Por ejemplo en el paro nacional y marcha del 21 de julio de 1999, donde la clave simbólica era llegar a la Capital Federal, a la Plaza de Mayo, para mostrarse y sensibilizar a los referentes nacionales de la difícil realidad del campo argentino y de las economías regionales, siempre ausente de las políticas nacionales. La presencia de la Mesa en esta manifestación llevó consigo la representatividad de las organizaciones y de los movimientos sociales más alejados y con mayores dificultades para acceder a la Capital Federal.

Por otra parte está la Federación Agraria Argentina (antigua entidad gremial, creada en 1912, de tercer grado y de alcance nacional) que ha aumentado, en la última década, su vinculación con los sectores agropecuarios más pequeños y pobres. Y es así como ha dirigido numerosas acciones de protesta contra el modelo neoliberal (sosteniendo que es el modelo más concentrador y excluyente que ha existido en la Argentina). A lo que debe agregarse el movimiento de confluencia y articulación que se está generando en el presente entre estas organizaciones nacionales con otras con intereses semejantes, como la Central de Trabajadores Argentinos (СТA) y el Movimiento de Mujeres en Lucha. Sin contar con el hecho de que la recesión y crisis actual están haciendo confluir en los movimientos de protesta a distintos sec- 
tores (estudiantes, desocupados, piqueteros, movimientos ambientalistas, profesionales, entidades de la Iglesia católica, ONG de promoción y desarrollo).

En lo que sigue veremos, en primer lugar, ejemplos de la provincia de Misiones. Tomamos esta provincia porque opinamos que aquí se dan posibilidades de un desarrollo rural alternativo. Es un ejemplo de algún modo paradigmático, ya que Misiones es donde los movimientos de productores y la dinámica local ha tenido un desarrollo muy superior al resto.

Luego expondremos sobre la situación de las ONG que actúan en el ámbito de desarrollo rural, ya que éstas deberían constituir otro de los pilares de la estrategia de transformación institucional que estamos postulando.

\subsection{El Movimiento Agrario Misionero y las Ferias Francas de Misiones $^{12}$}

Según Golsberg (1999), las condiciones que posibilitaron en 1987 el retorno del MAM -había surgido en 1971 en la etapa de las Ligas Agrarias- a la acción gremial tienen que ver con:

i. La vuelta de sus antiguos dirigentes y la necesidad de reencontrarse con su identidad;

ii. Una estrategia de construcción del poder a través de la ocupación de los distintos espacios clave que estuvieran al alcance, la concertación y la negociación;

iii. La extensión de la red de articulaciones hacia aquellas estrategias que facilitaban los recursos.

Esto significó, en este caso particular, un mayor acercamiento a las distintas estructuras de gobierno para la discusión permanente y la negociación. Golsberg (1999) afirma que de la concreción de lo anterior se desembocó, finalmente, en la creación de las Ferias Francas. En 1993 habían iniciado cursos de capacitación en mercados locales; por otra parte ya estaba divulgada la venta domiciliaria, sin mayores resultados económicos. Entonces “el MAM irrumpe en la escena con una alternativa concreta: la Feria Franca" (Golsberg, 1999). Un hecho que no es la repetición del modelo reivindicativo de protesta de los 70, sino, por el contrario, una propuesta técnico-productiva.

${ }^{12}$ La información de este apartado ha sido extraída en su mayoría de Golsberg (1999), aunque se ha actualizado alguna información con datos aportados por informantes calificados. 
Este proyecto contó con el apoyo político provincial y la participación de numerosas instituciones (PSA, Pro-Huerta, Cambio Rural, Red de Agricultura Orgánica de Misiones, Municipalidad de Oberá, Agencia de Extensión Rural Oberá). Antes de comenzar se hizo una visita de aprendizaje a la Feria Regional de hortigranjeros de Santa Rosa en Río Grande Do Sul, Brasil (en julio de 1995 se recorrió tanto la feria como las chacras de los productores).

La primera feria se inauguró en la localidad de Oberá, a los pocos días de regresar del viaje a Río Grande, el 26 de agosto de 1995, con apenas siete productores (en la actualidad ya suman 70). Esta primera feria resultó una experiencia muy positiva en términos de mejora en los ingresos monetarios de los productores, conformación de redes, capacitación en nuevas técnicas y producciones, promoción de redes de solidaridad y de organización de los productores y articulación con la problemática local de los municipios donde la feria se lleva a cabo.

En un comienzo, los comerciantes locales se quejaban de la competencia que los feriantes iban a hacerles con sus productos frescos (más aún cuando habían sido eximidos en 20\% del pago de impuestos). Pero rápidamente notaron los beneficios conexos que el aumento de los ingresos de la comunidad local implicaba para incrementar sus ventas de otros productos, los que los feriantes no estaban en condiciones de producir (como el arroz, o el azúcar).

El resultado fue que las ferias se fueron expandiendo por toda la provincia y crecen día a día. Según los últimos datos rebelados, en mayo de 2002 hay 40 ferias en Misiones que agrupan a 2,500 familias. Cada feria tiene su propia asociación y todas las asociaciones confluyen en la Interferia o Asociación de Ferias Francas de Misiones.

La feria ha posibilitado la inserción de los jóvenes en el mercado laboral, la capacitación de los feriantes a cargo de diferentes organizaciones, la diversificación de la producción de los $\mathrm{PP}$, el aumento de sus ingresos monetarios o bien la regularidad en su percepción, la conformación de asociaciones locales, la expansión de redes de solidaridad, el estrechamiento de vínculos con la población local y con los consumidores: en definitiva, la conexión con la problemática de cada lugar.

Puede afirmarse que la potencialidad de las ferias hacia un desarrollo local alternativo es muy grande. Es una realidad que, entendemos, debe ser más analizada, para adentrarse en su com- 
plejidad y avanzar en sus claves y limitantes, y poder aprehender y replicar con éxito esta rica experiencia. Son este tipo de experiencias las que creemos constituyen ejemplos para ir avanzando hacia la transformación institucional en los ámbitos locales, en primera instancia, y para, conjuntamente, ir modificando la praxis y las condiciones de vida de los habitantes locales y de los pequeños productores rurales.

\subsection{Las ONG de desarrollo rural}

Las ONG de desarrollo rural, contradictoriamente a otras organizaciones, lograron subsistir durante la dictadura. ${ }^{13}$ Luego, durante la década de los 80, las ONG constituyeron, también, una alternativa a la crisis de los sistemas públicos de prestación social. En esos años, la problemática que centraba el interés de la mayoría era la pobreza rural. ${ }^{14}$

Con la vuelta de la democracia (y especialmente hacia los años 90), algunas organizaciones de financiamiento internacional comenzaron a retirarse paulatinamente. ${ }^{15} \mathrm{Y}$, efectivamente, comenzó a aparecer el Estado nacional como alternativa financiera para las ONG con una participación creciente. ${ }^{16}$

Es decir, una nueva política económica puso en manos de la sociedad civil parte de las tareas sociales que tradicionalmente habían correspondido al ámbito de lo público. Y esto se fue dando desde los años 80 , y especialmente en los 90, a través de pro-

\footnotetext{
${ }^{13}$ Esto fue producto del apoyo internacional. Algunas organizaciones europeas y americanas, conscientes de la situación de persecución y violencia que se vivía en la Argentina, dieron recursos para este sector; con ello se buscaba mantener en algunas áreas la ayuda social y evitar mayores procesos migratorios de técnicos y profesionales contrarios al régimen. Estos financiamientos para las ONG provinieron de fuentes como Misereor, Pan para el Mundo, Interamerican Foundation, SAREC y otras organizaciones europeas y americanas.

${ }^{14}$ Esta importancia sectorial relativa comenzó a cambiar en la década de los 90, en favor de un mayor número de ONG dedicadas a la atención de los sectores urbanos pobres.

${ }^{15}$ Esto sucedió por no ser Argentina un país prioritario en términos de índices de pobreza. Y porque instalada la democracia se estimó que existirían condiciones para que las ONG accedieran a otros recursos alternativos. Y también, porque se consideraba que las ONG existentes ya se encontraban consolidadas para emprender una tarea más independiente en la búsqueda de financiamiento. Esto último fue parcialmente cierto, y válido para algunas. Pues hay que tener presente que en este universo hay notorias diferencias en materia de objetivos, métodos, historias y tipos de vinculaciones con el Estado y la política nacional.

${ }^{16}$ En realidad, lo que ocurrió fue la cada vez menor participación del sector público en la problemática social, producto del modelo neoliberal y del ajuste. La ausencia del Estado pretende compensarse con las acciones de las ONG en la ejecución de las políticas sociales. La argumentación es que éstas tendrían beneficios operacionales, con menores
} 
gramas de asistencia y desarrollo social, financiados fundamentalmente con recursos multinacionales. ${ }^{17}$

Desde entonces, la intervención de las ONG -específicamente las vinculadas con el desarrollo- en las políticas sociales se ha caracterizado por un gran dinamismo, tanto por su crecimiento acelerado, como por la diversificación de sus campos de acción (Palomares et al., 1996: 87).

En definitiva, el boom de las acciones de las ONG de desarrollo aparece con la presión de los organismos multilaterales a los gobiernos nacionales para que las incorporen en la ejecución de sus políticas. Los organismos de financiamiento internacional vienen exigiendo que parte de los fondos de los proyectos financiados por ellos se canalicen a la población a través de la terciarización de ciertas actividades en favor de las ONG.

De todos modos, corresponde advertir que el surgimiento de nuevas ONG, como resultado de la fuerte demanda operada, no siempre implicó la solvencia y capacidad necesaria requerida por la actividad en cuestión. Asimismo, que al depender del Estado, la acción de las ONG se tornó muy vulnerable por la discontinuidad del financiamiento público, producto de la cambiante e inestable coyuntura política nacional, y por los cortos plazos para los que se otorgaron recursos (un año).

En el ámbito rural y especializadas en desarrollo rural existen pocas ONG con historia y experiencia de trabajo. Las de más antigua trayectoria con el sector son: INCUPO (Instituto de Cultura Popular), INDES (Instituto de Desarrollo Social y Promoción Humana), FUNDAPAZ (Fundación para el Desarrollo en Justicia y Paz). Un estudio sobre estas instituciones (Cowan Ros, 2000: 105) ha estimado que en 1988 había unas veinte oNG de desarrollo rural operando en la Argentina, con un presupuesto anual para 1998 de 10.4 millones de dólares (520 mil dólares anuales por ONG), aunque hay mucha heterogeneidad entre ellas. Unas pocas, las más antiguas (o de primera generación, las que devienen desde fines de los años 60 hasta 1975) manejarían anualmente las mayores cifras (cercanas a los 900 mil dólares por año). Pero la ma-

\footnotetext{
costos operativos, y contribuirían a dar intervención y comprometer a la sociedad civil en temas públicos.

${ }^{17}$ Banco Interamericano de Desarrollo, BIRF, Banco Mundial, Fondo Internacional de Desarrollo Agropecuario.
} 
yoría tendría presupuestos inferiores a los 150 mil dólares anuales. ${ }^{18}$

Según este mismo estudio (Cowan Ros, 2000: 104) las ONG de desarrollo rural habrían atendido a 23,200 familias rurales, la mayoría de ellas localizadas en las provincias del norte argentino (44\% localizadas en el noroeste, $42 \%$ en el noreste, $13 \%$ en la Patagonia, y cifras muy insignificantes en las regiones de Cuyo y Pampeana). A través del estudio de Cowan, se observa que ha habido un cambio en el peso regional de las familias atendidas. Históricamente las acciones de las primeras ONG se concentraron casi exclusivamente en el noreste argentino, y es a partir de la vuelta a la democracia que aparece el noroeste como un nuevo ámbito de operación, tanto de las antiguas ONG como de las nuevas. Lo cual sería producto del cambio operado en la década de los 90 y vinculado con la creciente participación del Estado nacional en el financiamiento.

Evidentemente, el número de familias atendidas y el presupuesto destinado en 1998 constituye una cifra no despreciable de la importancia de la acción conjunta de las ONG en el país; más aún, al pensar que el presupuesto anual de uno de los programas nacionales más importantes (PSA) es equivalente a la cifra dada por Cowan para el conjunto de las ONG. Del mismo modo, puede pensarse la población atendida, comparándola con los beneficiarios de algunos de los programas que figuran en el cuadro 1.

Sin embargo, es cierto que estas magnitudes tienen estrecha vinculación y dependencia con los programas nacionales antes mencionados. Hay una alta proporción de estos beneficiarios y de estos fondos cuyo destino depende de lo que suceda con los programas nacionales. De aquí la vulnerabilidad de estas acciones ante la precariedad con que en el Estado se maneja la política de desarrollo rural, la falta de apoyo político para el diseño de una estrategia de desarrollo rural, y en definitiva la latente presencia de inestabilidad política y social resultante del excluyente modelo económico.

Consideramos importante recuperar, como fuente de aprendizaje y capacitación, las modalidades de intervención de aquellas ONG que han logrado una estrecha, duradera y transformadora acción con los pequeños productores, han contribuido a la

${ }^{18}$ Nótese que estos datos corresponden al periodo de la convertibilidad, es decir son anteriores a la altísima devaluación producida a partir de enero de 2002. Por lo tanto, seguramente estas cifras deben haberse reducido en la actualidad, también en valores muy significativos, quizá hasta en $50 \%$ o aun más. 
multiplicación de las organizaciones de pp -como el caso de UN.PE.PRO.CH y otras- $y$ han recuperado organizaciones gremiales diezmadas por la dictadura.

\section{Conclusiones}

Al observar la situación institucional y de gestión global del desarrollo rural, en parte desde la perspectiva nacional, y en parte desde la provincial, y cotejándola con nuestra perspectiva teórica, queda claro que un modelo de desarrollo rural alternativo en Argentina demandará un largo proceso de participación social que construya capacidades y forme dirigentes.

Y esto es consecuencia de varias cuestiones. En primer lugar, de la falta de interés desde el poder (nacional y provincial) por estructurar una política y una estrategia de desarrollo rural que marque el rumbo a seguir con coherencia interna. El desarrollo rural en Argentina es una sumatoria de acciones, cada cual con su propia dinámica y sello (según qué programa se observe, qué provincia e incluso qué ámbito local y qué participantes están involucrados).

Lo anterior lleva, por su parte, a una conformación institucional nacional y provincial muy precaria y sin recursos, humanos o materiales en la materia. Y ello sin contar con el juego de alianzas y luchas internas entre los poderes del Estado y el manejo arbitrario y clientelar que de estas cuestiones se suele hacer desde el poder político.

De todos modos aquí corresponde diferenciar entre el accionar poco o nada transparente de buena parte de los políticos que tienen cargos electivos y pretenden imponer la dirección de las políticas de Estado y el de los funcionarios y profesionales y técnicos que llevan adelante los programas de desarrollo rural. Por diferentes circunstancias, suele suceder que éstos no tengan relación directa o de subordinación con aquéllos. Y, entonces, es más común que los responsables de los programas puedan y tengan un comportamiento serio y consecuente con los objetivos particulares de sus respectivas áreas, aun siendo frecuentemente asediados por los políticos para que revean sus acciones en su beneficio particular, o en el del partido que representan. Aún así, no es extraño que se vean en dificultades para cumplir con la estrategia de sus programas, por los diferentes obstáculos que los referentes políticos locales y provinciales diseñan e instrumentan cuando no se alían a sus prácticas prebendarias. Con lo cual los 
que en definitiva siempre pierden son los beneficiarios de los programas, por superposición de acciones, actividades contrapuestas, manejo inadecuado o contradicciones en sus procesos de aprendizaje y participación, etcétera.

Incluso así y a pesar de todas estas debilidades y envilecimientos múltiples, aparecen indicadores que estarían mostrando que en ciertas zonas se ha dado una confluencia de factores que estarían contribuyendo a la conformación de un modelo de desarrollo rural con mayor integración al desarrollo local de la comunidad respectiva, más interactivo entre los sectores involucrados y con un mayor compromiso de parte de los mismos. En este trabajo relevamos el caso de la provincia de Misiones, con su experiencia de las ferias francas, que auguran indicios al respecto. Pero sabemos que hay otros. Sólo en el caso de las ferias francas ya son ocho provincias que se han sumado a esta experiencia, habiendo 120 ferias distribuidas por todo el país.

Se trata de casos donde confluyen, por un lado, diversos programas e instituciones, nacionales, provinciales y locales, con objetivos comunes y serios en favor de la promoción de un desarrollo rural participativo, y por otro, diversos sectores provinciales y locales (públicos y privados) apoyando estas nuevas experiencias. Pero son, fundamentalmente, ámbitos donde se ha dado una movilización social importante, cadenas y redes de solidaridad. En lo cual tiene mucho que ver el accionar de renovadas organizaciones representativas de los intereses de los productores pequeños en general -como el MAM- y el de ONG de consolidada y reconocida trayectoria. Y es esta fuerte movilización representativa lo que ha fortalecido a beneficiarios y técnicos y los ha armado de recursos para afrontar los embates disruptores originados en otros sectores (políticos, empresariales y sindicales) que se sienten amenazados por estas experiencias.

La provincia de Corrientes es otro caso que merece una mirada especial desde la perspectiva de la acción local en la búsqueda de alternativas de desarrollo rural. En este caso, cuenta la existencia de una institución previa a los programas de desarrollo rural (la SAPP), que con objetivos y estrategias definidos facilitó y ayudó al posterior accionar de las organizaciones de PP.

Creemos que en estos dos casos no es indiferente el hecho de que en ambos, Misiones y Corrientes, confluyan al promediar los años 90 dos programas nacionales de desarrollo rural (PSA y PPNEA), con sus propias estrategias, en parte complementarias y en parte contradictorias. Pero que, en definitiva, a través de téc- 
nicos y dirigentes consecuentes contribuyeron a una penetración y comprensión más profunda de la problemática del sector y permearon con mayor fuerza a la sociedad local en su conjunto. Esto se observa a través de instituciones locales más consolidadas, con objetivos definidos, en la presencia de organizaciones reconocidas de pequeños productores, como el mam, la Asociación Provincial de Pequeños Productores Correntinos o la Federación Correntina de Asociaciones y Cooperativas de Productores.

En definitiva, casos como estos confirman la fuerza de transformación que pueden llegar a producir las instituciones que funcionan de manera regular, promoviendo formas transparentes y participativas y sostenidas en acciones transversales, en las que participan tanto el Estado, los productores como la sociedad local en general. Y esto es posible cuando existe una propuesta de participación y organización para los actores interesados, con dirección y capacidad de acción y con capacitación para esos mismos actores.

De todos modos, falta mucho todavía en el sendero de esta investigación dirigida a reconocer estos y otros casos similares, buscando parámetros que los expliquen e identifiquen, y que al mismo tiempo puedan ser utilizados para la promoción de políticas de transformación institucional y, consecuentemente, de desarrollo socioeconómico alternativo.

\section{Bibliografía}

Beinstein, Jorge (1999), La larga crisis de la economía global, Corregidor, Buenos Aires.

Benencia, Roberto (1999), Formas de construcción del poder entre pequeños productores rurales. Experiencias de organización en noreste argentino, mimeo, FAUBA, Buenos Aires.

Borja, J. y M. Castells (1998), Local y global, la gestión de las ciudades en la era de la información, Taurus, Madrid.

Boscherini, F. y L. Poma (2000), “Introducción” y "Más allá de los distritos industriales: el nuevo concepto de territorio en el marco de la economía global”, en F. Boscherini, y L. Poma (comps.), Territorio, conocimiento y competitividad de las empresas, Miño y Dávila Edit., Buenos Aires, pp. 15-38. 
Brett, E.A. (1999a), "Understanding institutions and organisations", in D. Robinson et al., Managing development: Understanding inter-organizational relationships, London, Sage, pp. 17-48.

Bret, E.A. (1999b), Participation and accountability in development management, mimeo, Development Studies Institute, London School of Economics, London.

Coraggio, José L. (1997), Descentralización, el día después, Cuadernos de Postgrado, CBC-UBA, Buenos Aires.

Cowan Ros, Carlos (2000), “ONG's de desarrollo rural: estructura, dimensión y desafíos ante el nuevo siglo", Realidad Económica 176, IADE, Buenos Aires, pp. 99-115.

Gilly, J.P. y A. Torre (2000), "Proximidad y dinámicas territoriales", en F. Boscherini y L. Poma (comp.), Territorio, conocimiento y competitividad de las empresas, Miño y Dávila Edit., Buenos Aires, pp. 259-294.

Golsberg, Celeste (1999), El Movimiento Agrario de Misiones en los nuevos escenarios, mimeo, faUBA, Buenos Aires.

Manzanal, Mabel (1998), "Vicisitudes de la comercialización de hortalizas entre los pequeños productores agropecuarios (el caso de la producción de tomate fresco en Cachi, Salta)", en Realidad Económica 153, IADE, Buenos Aires, pp. 58-75.

Manzanal, Mabel (2000), "Los programas de desarrollo rural en la Argentina (en el contexto del ajuste macroeconómico neoliberal)", Eure. Revista Latinoamericana de Estudios Urbano Regionales, vol. XXVI, núm. 78, septiembre, Instituto de Estudios Urbanos, Pontificia Universidad Católica de Chile, Santiago de Chile, pp. 77-103.

North, Douglass (1995), "The new institutional economics and third world development", en J. Harris, J. Hunter and C. Lewis (eds.), The new institutional economics and third world develpment, Routledge, London, pp.17-26. 
Oszlak, Oscar (2001), "El estado transversal”, en Encrucijada UBA, núm. 6, Revista de la Universidad de Buenos Aires, Buenos Aires, abril, pp. 30-41.

Palomares, Marta, et al. (comp.) (1996), Las ONG's y los pequenos emprendimientos ante los desafíos del Mercosur, Comisión Mercosur y Encuentro de Entidades no Gubernamentales, Buenos Aires.

Poma, Lucio (2000), "La producción de conocimiento. Nuevas dinámicas competitivas para el territorio", en F. Boscherini, y L. Poma (comp.), Territorio, conocimiento y competitividad de las empresas, Miño y Dávila Edit., Buenos Aires, pp. 373-422.

PROINDER (1998), Taller de diagnóstico de la capacidad institucional para el desarrollo rural de las provincias, mimeo, SAGPYA, Buenos Aires.

PROINDER (1999), Diagnóstico de la situación de desarrollo rural provincial en el inicio del PROINDER, mimeo, SAGPYA, Fortalecimiento Institucional, Buenos Aires.

Rosanvallon, Pierre (1995), La nueva cuestión social: repensar el estado providencia, Ediciones Manatial, Buenos Aires.

SAGPYA (2000), Los programas nacionales de desarrollo rural ejecutados en el ámbito de la SAGPYA, Serie Estudios e Investigaciones 1, PROINDER, Buenos Aires.

Enviado: 7 de marzo de 2002 Aceptado: 6 de junio de 2002 
